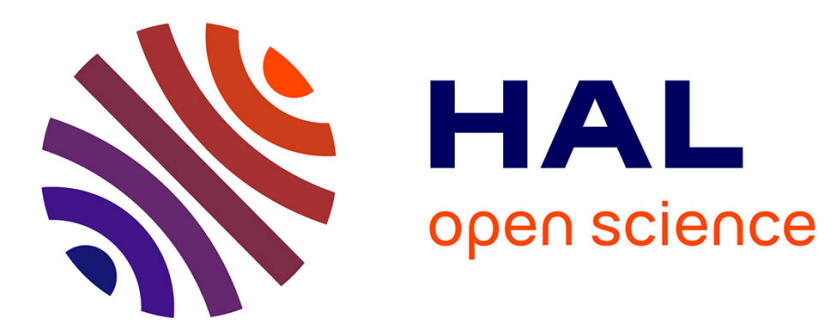

\title{
Digital Therapies
}

Robert J. Wierzbicki

\section{To cite this version:}

Robert J. Wierzbicki. Digital Therapies. 17th International Conference on Entertainment Computing (ICEC), Sep 2018, Poznan, Poland. pp.266-273, 10.1007/978-3-319-99426-0_28 . hal-02128624

\section{HAL Id: hal-02128624 \\ https://hal.inria.fr/hal-02128624}

Submitted on 14 May 2019

HAL is a multi-disciplinary open access archive for the deposit and dissemination of scientific research documents, whether they are published or not. The documents may come from teaching and research institutions in France or abroad, or from public or private research centers.
L'archive ouverte pluridisciplinaire HAL, est destinée au dépôt et à la diffusion de documents scientifiques de niveau recherche, publiés ou non, émanant des établissements d'enseignement et de recherche français ou étrangers, des laboratoires publics ou privés. 


\title{
Digital Therapies
}

\author{
Robert J. Wierzbicki \\ ${ }^{1}$ University of Applied Sciences Mittweida, Germany \\ robertewierzbicki.org
}

\begin{abstract}
Today, digital transformation and virtualization processes profoundly affect societies; not only in terms of socio-economic disruption, but also in terms of rising mental health problems. This paper focuses on the design aspects and the use of "nurture games" as a social utility of preventive measures (that is referred to in this paper as "Digital Therapies"), in the realm of nurturing and public school education, supporting therapeutic benefit and well-being. The Cognitive Behavioral Therapy (CBT), employed for treating a large number of mental problems, is considered here as a fundamental psychotherapeutic approach, which needs to underpin the design of games aiming to improve mental health and support the prevention of challenging behaviors in youth.
\end{abstract}

Keywords: digital therapy, cognitive behavioral therapy, mental health, behavior, game design, nurture games, game-like settings, blended nurture, therapeutic benefit, well-being, digital transformation, society.

\section{Behavior in Humans}

Human behavior is the result of different factors, including, amongst others, the organism's genetic composition and the interaction between heredity and environment [1]. The nature/nurture debate is still ongoing $[2,3]$, even if some geneticists might have declared it to be over [4].

Today, not only children and adolescents reveal emotional and behavioral problems [5]. Stress in the modern world can substantially bias the development of cognitive control processes in adults as well. This may not only increase the overall vulnerability to depression, anger and anxiety disorders, but also decrease one's ability to cope with unexpected stressful and tragic life events [6]. Dysfunctional patterns may help to cope with these situations but in the long term, they may cause severe or irreversible mental problems and result in abnormal behaviors as well as socialization styles and finally leading finally to mental self-destruction. 


\section{Mental Health in the Internet Age}

Human mental health condition and behavior are caused by a combination of genetic, biological, environmental, psychological, and, last but not least, technological factors. Internet, the greatest invention of the past few decades, has definitely made some negative impact on society. Moreover, relationship between internet technology and the individual has become increasingly problematic [3, 7]. As the virtualization of human life and the convergence of life and technology continue, more and more problems arise, depriving many of us of positive human qualities. Even good people may turn bad online [8]. Ever-changing subcultures and the behavioral transformation societies undergo is dramatically more accelerated and more psychologically formative than any previous technological transformation [9]. Mental health problems in young people seem to have increased considerably over the past 20 years. They are predominantly rooted in social change, including disruption of family structure, growing youth unemployment as well as increasing educational and vocational pressures [10]. The identification of mental health problems and disorders is complicated. Even the ones concerned may not be aware of a mental balance distortion already present. The list of mental health problems is long. It includes, among others, social anxiety, panic, depression, substance abuse, separation anxiety disorder, attention-deficit/hyperactivity disorder (ADHS), oppositional defiant disorder, pervasive developmental disorders (PDD) and post-traumatic stress disorder (PTSD) [11-13]. Many negative effects in mental health are caused or reinforced by the internet, tech usage and media consumption. Actions that children observe through the media become examples to follow [14]. Bringing up children in the internet age has become a great challenge. Letting children use tech products from an early age disturbs their overall development and distorts their perception of reality [15]. Tech ban, on the contrary, may result in problems integrating juveniles into digital society later in life. The long academic debate on the impact of violent games on behavior is finally over. It has been proven that violent video games are a causal risk factor for increased aggressive thoughts and behavior, decreased empathy, and decreased prosocial behavior in youths [16].

Internet-based problems like virtual violence and cyberbullying impact not only mental health but also the safety of teens and may result in their social isolation and sometimes even in suicide [17]. The prevalence of childhood psychiatric disorders appears to have been underestimated for a long time [18]. It seems more than obvious that preventive actions need to be taken.

\section{Psychotherapy}

Psychotherapy focuses on the significance or the relevance of our early childhood in our thinking and behavioral patterns [19]. Modern psychotherapy has been proven very useful for people who are struggling with longstanding difficulties. Especially psychoanalysis [20] and psychodynamics [21] have been accepted as useful in handling complex personality and behavior problems, even if modern psychology might find the 
therapy techniques not very effective in particular cases and the scientific evidence in support of the therapies may sometimes appear to be ambiguous [22].

Psychoanalysis emerged as a method of making the unconscious conscious, restoring the unity of the mind and its capacity for self-regulation [23]. The goals of psychodynamic therapy are a client's self-awareness and understanding of the influence of the past on present behavior [24].

Psychodynamic therapy, as opposed to psychoanalysis, does not need to include all analytic techniques (interpretation, transference analysis, technical neutrality and countertransference analysis [25]), and does not necessarily need to be conducted by psychoanalytically trained analysts.

\section{Cognitive Behavioral Therapy}

Cognitive Behavioral Therapy (CBT) is considered a holistic combination of both psychotherapy and behavioral therapy, the latter emphasizing on the close equation between our psychological problems, behavior patterns and thoughts [26]. CBT is a technique used to teach individuals to change their unwanted behaviors. A key cognitive concept in CBT is "guided discovery" [27] - a therapeutic stance which involves trying to understand the patients' view of things and help them expand their thinking, so that they become aware of their underlying assumptions, and discover alternative perspectives and solutions for themselves [28].

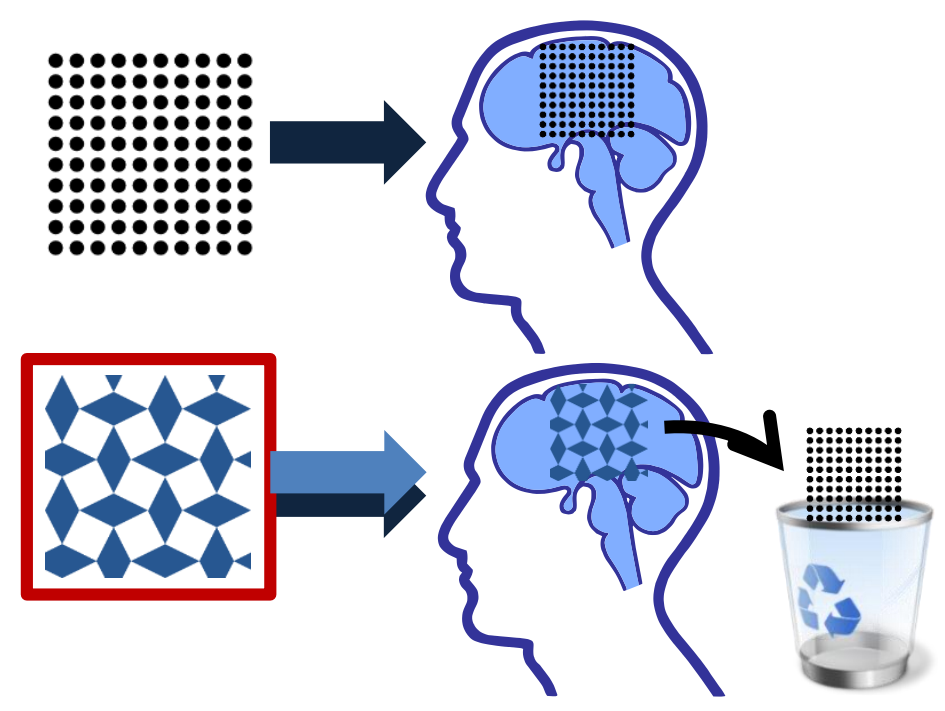

Fig. 1. The principle of changing behavioral patterns in a cognitive behavioral therapy. 
CBT is a collaborative approach. The therapist and client are regarded as equal members of a team, and the client takes substantial ownership over the direction of the course of treatment [29]. Different distressing feelings in humans relate to the neurotransmitter activity in the brain [30], attributed to physical sensations, and physiological and emotional input. Cognitive behavioral treatments can alter our perception of unpleasant sensations by altering sensory processing in the cortex [31]. Cognitive interventions, among others, may include exercises in perspective taking [32], distraction techniques [33], methods of relaxation (e.g. guided imagery [34], enhancing both physical and mental performance), rational problem solving [35], and the use of adaptive self-statements [36].

Many studies have assessed the efficacy of CBT interventions [37]. Originally developed for the treatment of depression, cognitive therapy has been applied successfully to a number of psychiatric conditions, including anxiety and mood disorders among children and youth [38]. The concept behind CBT refers to the so-called "cognitive restructuring" $[39,40]$ and is based upon an identification of factors affecting the individual's difficulties.

Powerful cognitive behavioral treatments with children and adolescents include stories, metaphors and analogies [41, 42]. Metaphors in CBT help understand complex reasoning behind conscious and subconscious decisions and help to cognitively restructure distorted schemas [43].

\section{Game as a Communication Channel}

Today, teaching in schools relies on different standard communication channels such as printed texts, workbooks, paper-and-pencil exercises or chalkboard demonstrations. In addition, there are mobile technologies, e-mails, messenger services, forums, and social networking, which are the most prominent from the digital area.

The choice of communication channels depends essentially on the instruction strategy, curriculum to be taught, type of blended learning arrangement, goals to be achieved and the media available.

Game as a communication channel is one of the latest technology-based additions to learning aids and tools, capable of enhancing the learning process in many areas. Serious games in education may serve as effective learning tools that engage and motivate learners [44]. It is, however, important to differentiate between a game sensu stricto and a "game-like" interactive setting. The first requires players to engage in an artificial conflict, defined by rules, that results in a quantifiable outcome [45]. An effective digital nurturing interactive setting may require a different perception of a "game", in which, for example, no quantifiable outcome needs to be generated. The focus may simply be put on playfully acquiring sensory impressions, emotive experiences, discov- 
ery and generating deep reflective thoughts - all aspects of cognitive behavioral therapy. The perception of such an environment as a game, no matter if single or collaborative, is still present because the action therein is rooted in game mechanics.

In one of my previous papers, I discussed an approach I call "Blended Nurture" [14], a concept that aims at changing social or personal behavior through participation in "nurture games" combined with a moderated live part settings which contain both the virtual and the real components.

\section{BLENDED NURTURE ARRANGEMENT}

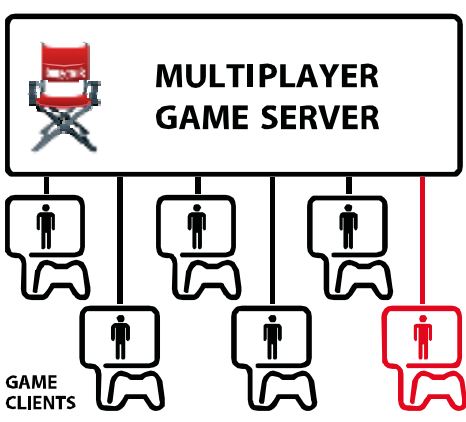

GAME PART

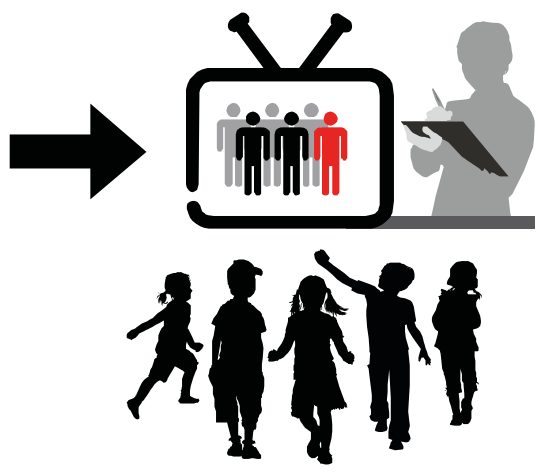

MODERATED PART

Fig. 2. "Blended Nurture" arrangement [14] .

A coach (therapist) must ensure that experiences are correctly classified and that correct behavioral patterns become embedded in the cognitive structures of the brain. A setting like this reflects the classical cognitive behavioral therapy model and is thus predestined as school-based prevention and intervention measures aimed at strengthening socialization, personality development, and mental health in young people. This requires, however, collaboration between schools and psychologists, which not always can be achieved.

Nurture game concepts often rely on common sense rather than on in-depth psychological knowledge and CBT-expertise. This is the reason, why games like these do not always fulfil the promise of boosting efficacy in education, especially at tackling mental health problems. Sometimes wrong assumptions are made. Always complying to the standard definition of a game formulated by Salen and Zimmerman [45] is in my option a mistake. Relying on "get started" reports utilizing this definition (e.g [46]) tempt game designers to think in terms of competitive settings, rules, scores, winning and losing, rewards and measurable outcomes, which is not the best starting point for the development of games in question. Another thing is that sometimes simple interactions 
and decision making, accentuated with appropriate (from the CBT point of view) storytelling contexts and metaphors, allow to achieve more than what a sophisticated multiplayer game may offer.

\section{Conclusion}

In this paper, I have discussed some basic aspects underlying creation and utilizing of "nurture games" as school-based prevention and intervention measures, aimed at strengthening socialization, personality development, and mental health in young people; "nurture" being understood as upbringing processes, promoting the development of children and adolescents on the way to adulthood.

Cognitive Behavioral Therapy (CBT) has been recognized in this paper as a fundament for the creation of games, which tackle psychological problems within a preventive context. Digital therapies, the CBT-based approaches in a digital domain, can help to cope with different social problems, sensitize to ethical questions, promote "correct" behavior as well as social and moral values. They can also help to reduce stress, relieve symptoms of depression and boost feelings of joy and well-being.

I claim that the standard definition of a game by Salen and Zimmerman [45] needs some refinement. It might be reasonable to recognize collecting experiences through interaction as a core aspect of a "game" rather, than gaining scores and achieving a quantifiable outcome. The modified perception of a game could perhaps provide a more consistent and unified view on what a game actually is, and would also allow to avoid debating on terminology and differentiation between "games", "serious games", "game-like environments" etc.

\section{References}

1. DiLalla, L.F., Gottesman, I.I. (eds.): Behavior genetics principles. Perspectives in development, personality, and psychopathology, 1st edn. Decade of behavior. American Psychological Association, Washington, DC (2004)

2. Robinson, G.E.: Beyond Nature and Nurture. Science (2004). doi: 10.1126/science.1095766

3. Robert J. Wierzbicki: The Convergence of Life and Technology from the Nurturing Perspective. The International Journal of Advanced Smart Convergence(Volume 3 No. 1), 7-10 (2014)

4. John Henry Horgan: Eugenics revisited. Scientific American 268 6, 122-131 (1993)

5. Gullotta, T.P., Plant, R.W., Evans, M.A. (eds.): Handbook of Adolescent Behavioral Problems. Evidence-Based Approaches to Prevention and Treatment, 2nd edn. Springer US, Boston, MA, s.l. (2015) 
6. Zarb, J.M.: Developmental cognitive behavioral therapy with adults. Routledge, New York (2007)

7. Gackenbach, J. (ed.): Psychology and the Internet. Intrapersonal, interpersonal, and transpersonal implications, 2nd edn. Elsevier, Amsterdam (2007)

8. Gaia Vince: Why good people turn bad online: Experts reveal how the internet boosts the 'personal rewards of expressing outrage'. http://www.dailymail.co.uk/sciencetech/article-5578675/Why-good-people-turn-bad-onlineExperts-say-internet-amplifies-rewards-expressing-outrage.html (2018)

9. Birkerts, S.: Changing the subject. Art and attention in the Internet age. Graywolf Press, Minneapolis, Minn. (2015)

10. Michaud, P.-A., Fombonne, E.: Common mental health problems. BMJ (Clinical research ed.) (2005). doi: 10.1136/bmj.330.7495.835

11. Costello, E.J., Mustillo, S., Erkanli, A., Keeler, G., Angold, A.: Prevalence and development of psychiatric disorders in childhood and adolescence. Archives of general psychiatry (2003). doi: 10.1001/archpsyc.60.8.837

12. Ford, T., Goodman, R., Meltzer, H.: The British Child and Adolescent Mental Health Survey 1999: the prevalence of DSM-IV disorders. Journal of the American Academy of Child and Adolescent Psychiatry (2003). doi: 10.1097/00004583-200310000-00011

13. Fombonne, E.: Epidemiological surveys of autism and other pervasive developmental disorders: an update. Journal of autism and developmental disorders 33(4), 365-382 (2003)

14. Robert J. Wierzbicki: Blended Nurture. In: Kim, T., Adeli, H., Kim, H.K., Kang, H., Kim, K.J., Kiumi, A., Kang, B.H. (eds.) Software Engineering, Business Continuity, and Education: International Conferences, ASEA, DRBC and EL 2011, Held as Part of the Future Generation Information Technology Conference, FGIT 2011, in Conjunction with GDC 2011, Jeju Island, Korea, December 8-10, 2011. Proceedings, pp. 643-649. Springer Berlin Heidelberg (2011)

15. Spitzer, M.: Digitale Demenz. Wie wir uns und unsere Kinder um den Verstand bringen. Droemer, München (2014)

16. Anderson, C.A., Shibuya, A., Ihori, N., Swing, E.L., Bushman, B.J., Sakamoto, A., Rothstein, H.R., Saleem, M.: Violent video game effects on aggression, empathy, and prosocial behavior in eastern and western countries: a meta-analytic review. Psychological bulletin (2010). doi: 10.1037/a0018251

17. Kowalski, R.M., Limber, S., Agatston, P.W.: Cyberbullying. Bullying in the digital age, 2nd edn. Wiley-Blackwell, Malden, MA (2012)

18. Ramchandani, P.: Prevalence of childhood psychiatric disorders may be underestimated. Evidence-based mental health 7(2), 59 (2004)

19. Bor, R., Palmer, S. (eds.): A beginner's guide to training in counselling \& psychotherapy. SAGE Publications, London, Thousand Oaks, Calif (2002)

20. Freud, S.: General introduction to psychoanalysis. Createspace Independent, [Place of publication not identified] (2012)

21. Ahles, S.R.: Our inner world. A guide to psychodynamics \& psychotherapy. Johns Hopkins University Press, Baltimore, Md. (2004) 
22. Fonagy, P.: The effectiveness of psychodynamic psychotherapies: An update. World psychiatry : official journal of the World Psychiatric Association (WPA) (2015). doi: 10.1002/wps.20235

23. Michael J. Diamond, Christopher Christian: The second century of psychoanalysis. Evolving perspectives on therapeutic action. CIPS series on the boundaries of psychoanalysis. Karnac, London (2011)

24. Jim Haggerty: Psychodynamic Therapy. Psych Central. https://psychcentral.com/lib/psychodynamic-therapy/ (2018)

25. Kernberg, O.F.: The four basic components of psychoanalytic technique and derived psychoanalytic psychotherapies. World psychiatry : official journal of the World Psychiatric Association (WPA) (2016). doi: 10.1002/wps.20368

26. Muntau, G.: Cognitive Behavioral Therapy: Master Your Brain, Depression and Anxiety. CreateSpace Independent Publishing Platform (2017)

27. Padesky, C.A.: Schema change processes in cognitive therapy. Clin. Psychol. Psychother. (1994). doi: 10.1002/cpp.5640010502

28. Miss Kristina Fenn, Dr Majella Byrne: The key principles of cognitive behavioural therapy. InnovAiT (2013). doi: 10.1177/1755738012471029

29. Wenzel, A., Kleiman, K.R.: Cognitive behavioral therapy for perinatal distress. Routledge/Taylor \& Francis Group; Routledge, New York NY, US (2015)

30. Panksepp, J.: Affective neuroscience. The foundations of human and animal emotions. Series in affective science. Oxford Univ. Press, Oxford (2005)

31. Chisholm-Burns, M., Schwinghammer, T., Wells, B.G., Wells, B., Malone, P., Dipiro, J. (eds.): Pharmacotherapy Principles and Practice, Third Edition, 3rd edn. McGraw-Hill Publishing, New York (2013)

32. Harwood, M.D., Farrar, M.J.: Conflicting emotions: The connection between affective perspective taking and theory of mind. British Journal of Developmental Psychology, 24 (2): 401-418 (2006)

33. Briers, S.: Brilliant cognitive behavioural therapy. How to use CBT to improve your mind and your life, 2nd edn. Pearson, Harlow, England (2012)

34. Ackerman, C.J., Turkoski, B.: Using guided imagery to reduce pain and anxiety. Home Healthcare Nurse, 18(8) 524-530 (2000)

35. Nezu, A.M., Nezu, C.M., D'Zurilla, T.: Problem-Solving Therapy. A Treatment Manual. Springer Publishing Company, New York (2012)

36. Cristea, I., Szentagotai-Tatar, A., Lucacel, R.: Differential effects of self-statements following a self-esteem threatening situation. Journal of Evidence-Based Psychotherapies 14. 39-52 (2014)

37. Herbert, J.D., Evan M. Forman (eds.): Acceptance and mindfulness in cognitive behavior therapy. Understanding and applying the new therapies. Wiley (2011)

38. Reinecke, M.A., Dattilio, F.M., Freeman, A. (eds.): Cognitive therapy with children and adolescents. A casebook for clinical practice, 2nd edn. Guilford Press, New York (2003)

39. Ellis, A.: Reason and emotion in psychotherapy. Lyle Stuart, Oxford, England (1962)

40. Beck, A.T.: Cognitive therapy and the emotional disorders. International Universities Press, New York (1976) 
41. Blenkiron, P.: Stories and Analogies in Cognitive Behaviour Therapy: A Clinical Review. Behav. Cognit. Psychother. (1999). doi:

10.1017/S1352465804001766

42. Wierzbicki, R.J., Bohnke, P.: Exploiting Convergence of Life with Technology to Tackle Real-Life Problems by Means of Computer Games. International journal of advanced smart convergence (2013). doi: 10.7236/IJASC2013.2.2.1

43. Spiegler, M.D., Guevremont, D.C. (eds.): Contemporary behavior therapy, 5th edn. Wadsworth, Cengage Learning, Belmont, CA (2010)

44. Li, J.: Video games in classrooms: an interview with Zack Gilbert. On the Horizon (2016). doi: 10.1108/OTH-03-2016-0009

45. Salen, K., Zimmerman, E.: Rules of play. Game design fundamentals. The MIT Press, Cambridge, Mass. [u.a.] (2010)

46. Baranowski, T., Buday, R., Thompson, D., Lyons, E.J., Lu, A.S., Baranowski, J.: Developing Games for Health Behavior Change: Getting Started. Games For Health Journal (2013). doi: 10.1089/g4h.2013.0048 